With regard to the later history of these cases, I can report that both patients are well now; no recurrence of the discharge. Hearing improved in the first patient and was not influenced in the second.

\title{
A CONTRIBUTION TO THE TREATMENT OF ACUTE CATARRH OF THE NOSE.
}

\author{
By Dr. R. Spura, \\ Director of the Department for Diseases of the Ear and Nose, \\ Jewish Hospital, Krakau.
}

IT is known to all physicians what difficulties the treatment of the above-mentioned trouble presents, while the remedies recommended for it are numerous. Nevertheless, there is not one among them which can be used to the full satisfaction of the patients, nor one hitherto proved to be entirely effectual. It is therefore natural that the physicians should still be always seeking and looking out for a remedy which could be used with full satisfaction.

I will not mention, and will rather look away from, the trials and experiments I have made with different remedies and methods in this disorder. I will rather place before the readers of this JouRnal the experience I have lately had with a new remedy.

In cases of acute catarrh of the nose, and especially violent dry colds, causing stoppage in the nose, I have seen such excellent results obtained with adrenalin inhalant, that I consider it my duty to draw attention to this preparation. This consists of one part of adrenalin hydrochloride to 1000 parts of a very pleasant scented, aromatic neutral oil basis with 3 per cent. chloretone, which is prepared and brought into the market by a well-known firm of chemists in London. It is a familiar fact that considerable relief can be obtained with any supra-renal preparation in combination with a cocaine solution in such cases. But, firstly, this effect is only a passing one of short duration, secondly, these remedies, if used often, have various inconvenient and unpleasant after-effects, which render the frequent application inadvisable. With adrenalin inhalant the effect is more lasting, and then, if not used too often, it is free from unpleasant aftereffects. This medicament should be applied in the form of sprays in the nose, or by painting the nasal mucous membrane two or 
three times a day by means of a piece of a probe enveloped in wadding and dipped into the solution.

At intervals I am in the habit, from time to time, of painting the mucous membrane of the nose with coryphin, a menthol-ester produced and brought into trade by a well-known firm at Elberfeld, which has proved to be a remedy with agreeable, healing and advantageous properties.

Who does not know the extremely painful condition accompanying the "stoppage in the head"? In the nose there is a burdensome feeling of fulness, straining and often also of tickling, the mouth open, the throat dry, the eyes heavy, dull and burning, the head stupid and disturbed. In the region of the forehead and temple a sensation of overcharging and obtuseness, mental heaviness, the slumber uneasy and interrupted, or even impossible.

In that state I have found, especially before going to bed, when all these complaints are apt to be at their worst, the following proceeding exceedingly effective and beneficent: Painting the nasal mucous membrane with the above-mentioned preparation, or instilling a few drops of it into the nose, brushing the region of the temples and the brow with coryphin, and taking aspirin $(0.5 \mathrm{grm}$. internally (per os). The nose becomes quickly pervious, the head free and clear, the eyes brighten as if relieved from a heavy pressure, and the breathing becomes also lightened and easy. The patient feels himself greatly relieved, and reanimated, and with the return of respiration through the nose sleep again becomes possible, and calm and easy.

It is likely that this remedy may be proved in many cases also as a very effective prophylactic against the complications of the hearing organ which so often occur.

In the acute catarrh of the nose in suckling babies, in whom this disease, on account of the difficulty in taking of nourishment, involves sometimes a very grievous affection, and which may even be dangerous to life, I have not as yet tried this remedy. I order from time to time as hitherto, with good success, particularly before going to bed, instillations into the nose of one to two drops of a 1 per cent. solution of cocaine, to which is added adrenalin in the proportion of one drop to ten of the solution. Through the momentary detumescence of the mucous membrane thus brought about, the permeability of the nasal cavities is restored, feeding again becomes possible, and-sleep, hitherto disturbed and uneasy, 
is again calm and easy. At any rate, however, it would be recommendable to try also in such cases a diluted oily solution of adrenalin inhalant.

\section{STREPTOCOCCAL ("SEPTIC") THROATS.1}

Annotation.

Dr. J. O. Hollick, medical officer to the Midland Counties' Idiot Asylum, gives an interesting account of an outbreak which occurred in that institution in 1908 of a pharyngitis and tonsillitis of an infectious nature, at first thought to be due to the Klebs-Loeffler bacillus. Subsequent examination showed, however, an absence of diphtheria bacilli but plentiful streptococci and staphylococci.

The general symptoms were as follows: Feeling of malaise, pains in the back and in the neck up to the occiput, and headache. The evening temperature often rose to $104^{\circ} \mathrm{F}$. and the morning temperature to $100^{\circ} \mathrm{F}$. Slight soreness on one or both sides and difficulty of swallowing; the submaxillary and glands adjacent to the angle of the jaw and in the triangles of the neck were slightly enlarged and tender. Tonsils showed creamy-white secretion with angrylooking areola of inflammation extending to the anterior pillar of the fauces, the uvula swollen and intensely odematous. No follicular exudation on the tonsils. The urine was febrile, and in some showed slight trace of albumen. In from two to four days the symptoms and local signs decreased, the glandular swelling and tenderness remaining for some days after the clearing up of the throat symptoms. In connection with this epidemic two cases of cutaneous erysipelas of the foot and leg occurred. Several of the patients with the throat symptoms and glandular enlargements showed a tendency to relapse if allowed to get up within too short a periud of subsidence of temperature.

With regard to treatment, all were isolated at once on rise of temperature, or on complaint of soreness of throat, and owing to this precaution in a colony of 160 people only 15 were affected with the malady. Formamint lozenges were sucked (three a day) by all not affected, and by those affected a lozenge every three hours, while frequent swabbing of the tonsils and pharynx with "izal" solution (suitably diluted) was resorted to. All cups, spoons, etc., used by the affected inmates were sterilised in formalin solution after use. In addition to the swabbing, spray-

1 Lancet, December 19, 1908. 